\title{
Communication
}

\section{APP and APLP1 are degraded through autophagy in response to proteasome inhibition in neuronal cells}

\author{
Fangfang Zhou ${ }^{1,2}$, Theo van Laar $^{2}$, Huizhe Huang ${ }^{1 凶}$, Long Zhang ${ }^{2 凶}$ \\ ${ }^{1}$ Faculty of Basic Medical Sciences, Medical College of Chongqing Medical University, Chongqing 400016, China \\ 2 Leiden University Medical Center, Department of Molecular Cell Biology, 2333 ZA Leiden, the Netherland \\ $\bowtie$ Correspondence: L.zhang@lumc.nl (L. Zhang), devbiology@cqmu.edu.cn (H. Huang) \\ Received April 17, 2011 Accepted May 2, 2011
}

\begin{abstract}
Amyloid beta (AB) precursor protein (APP) is a key protein in the pathogenesis of Alzheimer's disease (AD). Both APP and its paralogue APLP1 (amyloid beta precursor-like protein 1) have multiple functions in cell adhesion and proliferation. Previously it was thought that autophagy is a novel beta-amyloid peptide (A $\beta$ )-generating pathway activated in AD. However, the protein proteolysis of APLP1 is still largely unknown. The present study shows that APLP1 is rapidly degraded in neuronal cells in response to stresses, such as proteasome inhibition. Activation of the endoplasmic reticulum (ER) stress by proteasome inhibitors induces autophagy, causing reduction of mature APLP1/APP. Blocking autophagy or JNK stress kinase rescues the protein expression for both APP and APLP1. Therefore, our results suggest that APPIAPLP1 is degraded through autophagy and the APLP1 proteolysis is mainly mediated by autophagy-lysosome pathway.
\end{abstract}

KEYWORDS amyloid beta precursor-like protein 1 (APLP1), amyloid precursor protein (APP), proteasome inhibition, endoplasmic reticulum stress, autophagy, neuronal cells

\section{INTRODUCTION}

Amyloid precursor protein (APP), a key protein in pathogenesis of Alzheimer's disease (AD), is a type I transmembrane protein that can be cleaved by $\beta$ - and $\gamma$-secretase to release the amyloidogenic $\beta$-amyloid peptides $(A \beta)$ and intracellular domain (AICD) (Cao and Südhof, 2001; Aguzzi and Haass,
2003). $A \beta$ has been widely believed to initiate pathogenic cascades that culminate AD. The AICD was identified to form a multimeric complex with the nuclear adaptor protein Fe65 and the histone acetyltransferase Tip60 (Cao and Südhof, 2001). APP and its paralogue APLP1 (amyloid precursor-like protein 1 ) are processed in a very similar manner by the same protease activities; however, the APLP1 expression is limited to the nervous system, whereas APP is ubiquitously expressed (Tanzi et al., 1988).

APLP1 and APP have multiple functions, including promoting neurite outgrowth and cell proliferation; particularly, their ability to bind collagen and to mediate cell-substratum adhesion have been well-documented (Beyreuther et al., 1991; Chen and Yankner, 1991; Jin et al., 1994; Beyreuther et al., 1996; Coulson et al., 1997). Recently, the homo- and hetero-typic cis interactions of APP family members have been detected by fluorescence resonance energy transfer (FRET) and co-immunoprecipitation analysis (Soba et al., 2005; Kaden et al., 2009).

Lysosome and proteasome are the main systems for cells to digest or recycle proteins. It has been recognized that APP is degraded through lysosome, while the protein proteolysis of APLP1 is less understood (Cataldo et al., 1991; Golde et al., 1992). Autophagy refers to at least three processes by which intracellular constituents enter lysosomes for degradation: chaperone-mediated autophagy (CMA), microautophagy and macroautophagy. Autophagy is the sole pathway for organelle turnover in cells and is a vital pathway for degrading normal and aggregated proteins, particularly under stress or injury conditions. Recent evidence has shown that APP is processed by autophagy and the amyloid beta peptide is generated from APP during the autophagic turnover of APPrich organelles (Dash and Moore, 1993; Mizushima, 2005). 
However, whether APLP1 also goes to autophagy is still unknown.

Here, we found that blocking the proteasome by transient treatment with MG132 or lactacystin rapidly accelerates APP/ APLP1 protein turnover. Mechanistic study showed that the proteasome inhibition increases ER-stress and autophagy, and thus decreases APP/APLP1 protein expression without affecting their transcription. Autophagy marker protein LC3 can interact with APP/APLP1 in the presence of MG132 in neuronal cells. Induction of autophagy by rapamycin also decreases the APLP1/APP protein level. Blocking either autophagy or the JNK stress kinase obviously rescues APP/ APLP1 expression. Altogether, the present work implied that APP and APLP1 are degraded through autophagy in response to cell stresses in neuronal cells.

\section{RESULTS}

\section{Proteasome inhibition rapidly decreases APLP1 and APP protein expression in neuronal cells}

Expression of APLP1 is limited to the nervous system. To identify the pathway(s) mainly involved in the APLP1 protein proteolysis, $\mathrm{N}_{2}$ a cells were incubated with inhibitors that specifically block proteasome, lysosome or PI3K/MEK/cAMP kinase pathway. Instead of accumulating like $\beta$-catenin, protein expression of both APLP1 and APP rapidly decreased within $1 \mathrm{~h}$ upon proteasome inhibition by MG132 (Fig. 1A and 1B). Additionally, APLP1 protein also accumulated upon lysosome inhibition by $\mathrm{NC}\left(\mathrm{NH}_{4} \mathrm{Cl}\right)$, which was similar with the observations in APP protein. Further results also demonstrated that lower dose or short time treatment of proteasome inhibitor MG132 and lactacystiin could still suppress APLP1 and APP protein expression in a time- and dose-dependent manner (Fig.1C-E). These data indicate that APLP1 is mainly degraded through lysosome, which could be triggered by proteasome inhibition.

\section{Proteasome inhibition increases ER stress and decreases APLP1 protein stability without affecting APLP1 gene transcription in neural cells}

Next, we asked whether the loss of APP/APLP1 protein expression is due to transcriptional inhibition. Quantitative real-time RT-PCR results showed that MG132 has no effect on the transcriptional level of APP and APLP1 (Fig. 2A). However, upon the stimulation of MG132, accelerated turnover of APLP1 was observed using the protein synthesis inhibitor cycloheximide ( $\mathrm{CHX}$ ) in $\mathrm{N}_{2}$ a cells (Fig. 2B). Interestingly, the proteasome inhibition-accelerated turnover of APLP1 can be partially blocked by autophagy inhibitor 3MA (Fig. 2B). Similar result was also obtained using $\mathrm{NC}\left(\mathrm{NH}_{4} \mathrm{Cl}\right)$, which blocks both lysosome and autophagy (data not shown). This implied that autophagy is involved in the APLP1 protein proteolysis. Since the autophagy is a vital pathway for degrading normal and aggregated proteins, particularly under ER-stress or injury conditions, we determined the ER stress in the presence of proteasome inhibition. Similar with the positive control treated with tunicamycin, the ER-stress marker gene GRP78/Bip was clearly induced by proteasome inhibition in $\mathrm{N}_{2}$ a cells (Fig. $2 \mathrm{C}$ ).

\section{APPIAPLP1 is degraded through autophagy that is induced by proteasome inhibition}

Autophagy is an ER-stress release manner in cells; several reports demonstrated that the aggregated APP goes to autophagy. To explore the role of autophagy in APLP1 degradation, we firstly examined whether proteasome inhibition causes autophagy in neuronal cells. As shown in Fig. 3A, treatment of MG132 in $\mathrm{N}_{2}$ a cells led to LC3 cleavage (LC3 II) in a time- and dose-dependent manner. To validate this result, we further explored the localization of APLP1 in PC12 cells by immunofluorescence. As indicated in Fig. 3B, the proteasome inhibitor induced puncta of APLP1 was obviously detected. Thus, we hypothesized that LC3 may regulate APLP1 through direct interaction. To test whether APLP1 binds to LC3, we performed a co-immunoprecipitation assay in $\mathrm{N}_{2} \mathrm{a}$ cells. Both LC3 I and LC3 II were detected in anti-APLP1 or anti-APP immunoprecipitation but not in the control immunoprecipitated with a nonspecific antibody (Fig. 3C). To further confirm that APLP1 goes to autophagy, rapamycin was used to induce autophagy in $\mathrm{N}_{2}$ a cells. As shown in Fig. 3D, both rapamycin and MG132 induced autophagy (as shown in the cleavage of LC3 II) and decreased the protein expression of APLP1 and APP. The autophagy inhibitor 3MA could clearly rescue APP/APLP1 expression in lane 4 (Fig. 3D). Altogether, these results indiced that APLP1 was associated with LC3 and was degraded through autophagy, which was induced by proteasome inhibition.

\section{JNK kinase activity is required for APPIAPLP1 protein proteolysis in response to stress}

It is apparent that even transient inhibition of the ubiquitinproteasome system activates stress kinases. Thus, we investigated which kinase is critical for APP/APLP1 protein proteolysis in response to proteasome inhibitors. As shown in Fig. 4A, the specific JNK kinase inhibitor SP600125, but not the PI3K inhibitor LY294002, could partially rescue the APP/ APLP1 expression suppressed by MG132 (Fig. 4), suggesting that JNK kinase activity is required for APP/APLP1 protein proteolysis in response to cell stresses.

\section{DISCUSSION}

The present study showed for the first time that, similar with APP, APLP1 is mainly degraded through lysosome and can 
A
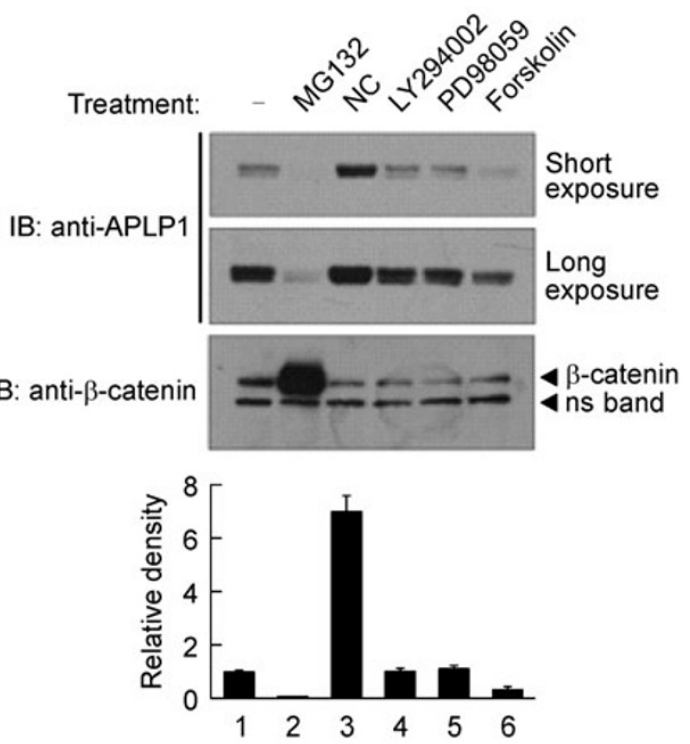

C

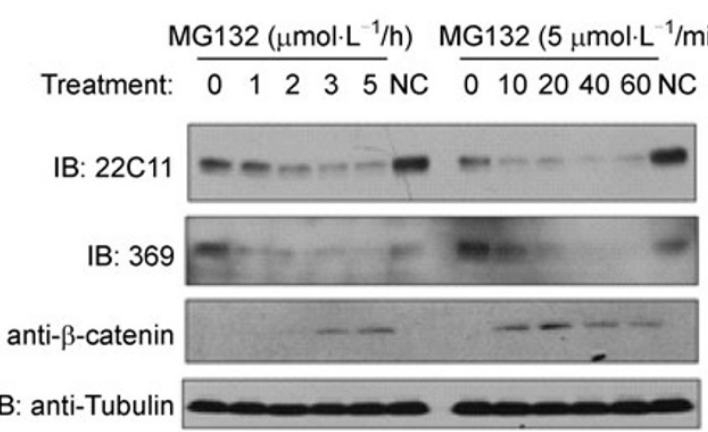

B

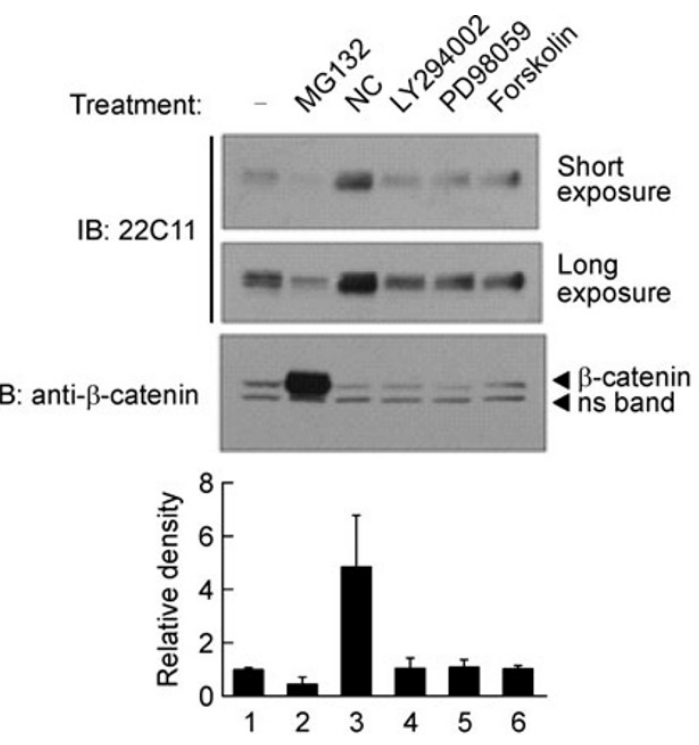

D

MG132 $\left(\mu \mathrm{mol} \cdot \mathrm{L}^{-1} / \mathrm{h}\right) \mathrm{MG} 132\left(5 \mu \mathrm{mol} \cdot \mathrm{L}^{-1} / \mathrm{min}\right)$

Treatment: $0 1 2 3 5 \mathrm { NC } \longdiv { 0 1 0 2 0 4 0 6 0 \mathrm { NC } }$

IB: anti-APLP1 $---\infty-\infty-\infty-\infty$

IB: anti-Tubulin $7-1-\ldots-m-1$

E

Lactacystin $\left(\mu \mathrm{mol} \cdot \mathrm{L}^{-1} / \mathrm{h}\right) \quad$ Lactacystin $\left(5 \mu \mathrm{mol} \cdot \mathrm{L}^{-1} / \mathrm{h}\right)$

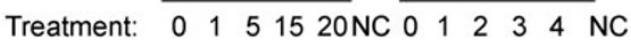

IB: anti-APLP1 $-m-m-\infty-m-m$

IB; anti-Tubulin $=--\infty-6-\infty-\infty-\infty$

IB: anti- $\beta$-catenin

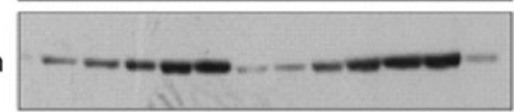

Figure 1. Proteasome inhibition rapidly decreases APLP1 and APP protein expression in neuronal cells. $\mathrm{N}_{2}$ a cells were incubated with or without inhibitors for $1 \mathrm{~h}$ and then harvested for anti-APLP1 (A) or anti-APP (B) immunoblotting. The concentration of cell lysate was measured with a BCA kit (Roche Applied Science) to ensure the same amount of total protein lysates for loading and the proteasome-degradative protein $\beta$-catenin was used as a control for the effect of MG132 (inhibitors: proteasome inhibitor 5 $\mu \mathrm{mol} / \mathrm{L}$ MG132, lysosome inhibitor $100 \mathrm{mmol} / \mathrm{L} \mathrm{NH}{ }_{4} \mathrm{Cl}(\mathrm{NC})$, PI3K inhibitor $10 \mu \mathrm{mol} / \mathrm{L} \mathrm{LY} 294002$, MEK inhibitor $10 \mu \mathrm{mol} / \mathrm{L}$ PD98059, and cAMP inhibitor $10 \mu \mathrm{mol} / \mathrm{L}$ Forskolin). Quantitative analysis was shown below $(n=3)$. (C) $\mathrm{N}_{2}$ a cells were incubated with MG132 at increasing doses for $1 \mathrm{~h}$ or at the same dose $(5 \mu \mathrm{mol} / \mathrm{L})$ for increasing time, and then cells were harvested for detection of endogenous APP level with $22 \mathrm{C} 11$ and 369 that recognize N-terminal and C-terminal of APP, respectively. $\mathrm{N}_{2}$ a cells were incubated with MG132 (D) or lactacystin A1 (E) at increasing doses or for increasing time, and then cells were harvested for detection of endogenous APLP1.

be sentenced to death in autophagy by cell stresses such as proteasome inhibition. Based on the above observations, it is likely that transient proteasome inhibition triggers autophagy and induces both APLP1 and APP degradation through autophagy, thus impairing the function of APLP1/APP in a JNK kinase-dependent manner. Since the depletion of APLP1 could impair neural cell adhesion, we accordingly observed the decrease of neural cell adhesion after MG132 treatment (data not shown). Usually, decrease of cell adhesion happens when cells tend to migrate or differentiate. We also found that proteasome inhibition induces neurite outgrowth of $\mathrm{N}_{2} \mathrm{a}$ and PC12 cells. Additionally, lacking of cell-cell conjunction was observed in MG132 treated neural cells. This may be correlated with the degradation of the homo- and heterodimer of APLP1 and APP (our unpublished data). These results suggested that cell stress might participate in the 

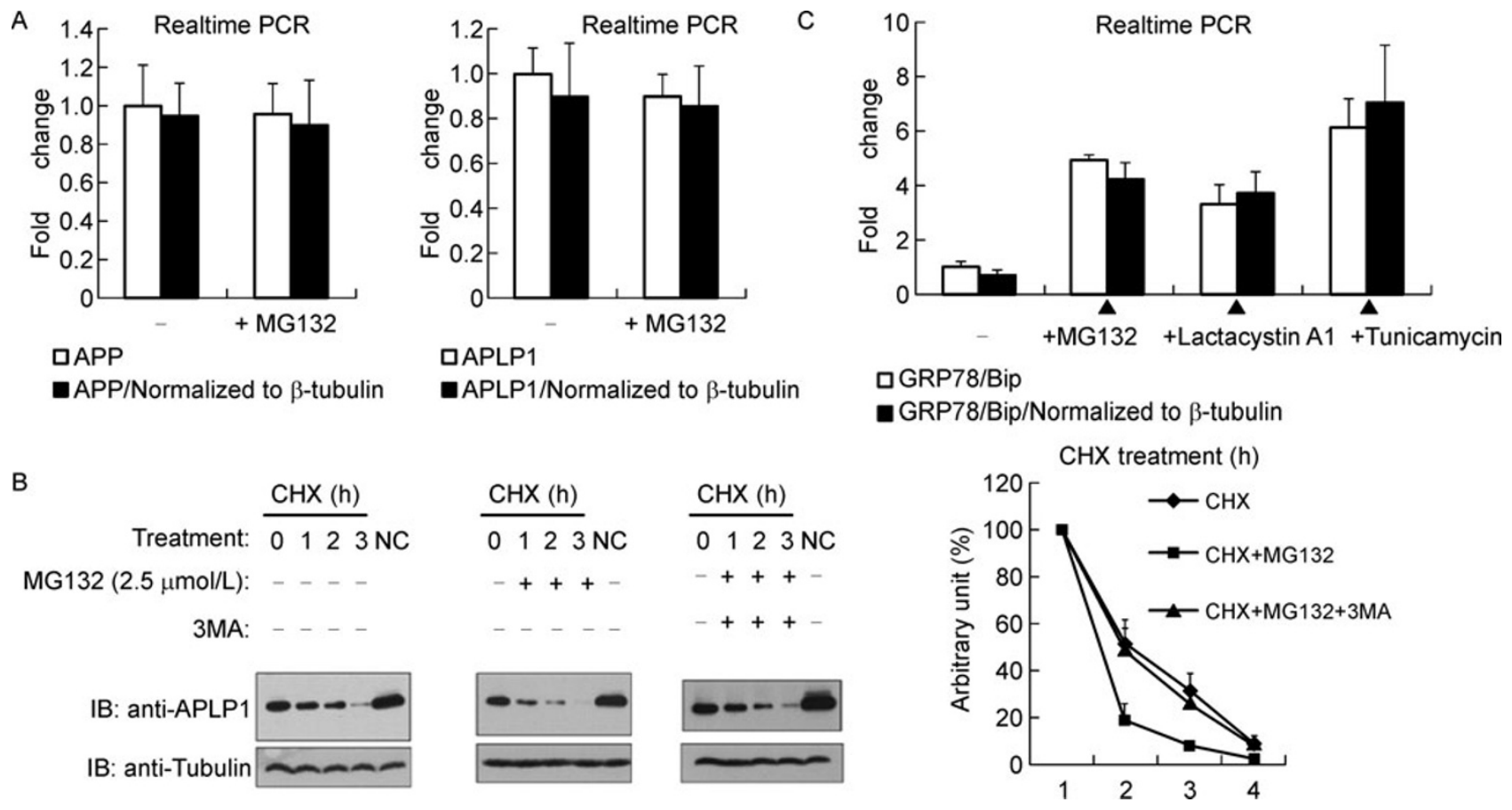

Figure 2. Proteasome inhibition increases ER stress and decreases APLP1 protein stability without affecting its transcriptional level. (A) $\mathrm{N}_{2}$ a cells were treated with or without $5 \mu \mathrm{mol} / \mathrm{L}$ MG132 for $2 \mathrm{~h}$. Total RNAs were then extracted, and quantitative real-time RT-PCR was performed. Both non-normalized (white) and $\beta$-tubulin normalized mRNA values (black) were depicted. (B) In the absence or presence of MG132 $(2.5 \mu \mathrm{mol} / \mathrm{L})$ and $3 M A, \mathrm{~N}_{2}$ a cells were treated with $\mathrm{CHX}(20 \mu \mathrm{g} / \mathrm{mL})$ for $0-3 \mathrm{~h}$ as indicated; Cells were then harvested for anti-tubulin or anti-APLP1 immunoblotting. The protein intensity was quantitated by BCA kit; equal amount of protein was loaded, and tubulin was used as loading control. The data shown at right are representative of three experiments. The protein level at time 0 was set as $100 \%(n=3)$. (C) $\mathrm{N}_{2}$ a cells were treated with inhibitors as indicated for $2 \mathrm{~h}$. Relative expression level of GRP78/Bip was detected by quantitative real time RT-PCR. Both non-normalized (white) and $\beta$-tubulin normalized mRNA values (black) were depicted.

neural cell function through modulating proteolysis and function of APLP1/APP protein. Our results also described APLP1 as a new lysosome-degraded protein that undergoes autophagy under ER-stress.

Although JIP-3/JNK has been proved to phosphorylate APP in vivo (Muresan and Muresan, 2005), proteasome inhibition could not induce APP phosphorylation (data not shown). Thus, our results support the previous study that APP phosphorylation, transport of generated pAPP into neurites, and neurite extension are interdependent processes regulated by JIP-3/JNK, and are in a pathway distinct from stressactivated JNK signaling. Recent studies showed that neuronal JNK deficiency affects autophagy in both cell culture and in vivo (Liang et al., 2010; Shimizu et al., 2010). Taken together, these results indicate that JNK kinase may play dual roles in regulating APP/APLP1.

Although $A D$ is a prevalent neurodegenerative disorder in elder people (Hedera and Turner, 2002) and a multifactorial syndrome, so far, it is mainly linked to the abnormal metabolism of transmembrane protein APP, rather than APLP1. APLP1 is processed similarly as APP by gammasecretase complex that contains presenilins, nicastrin, aph-1 and pen-2. Here, we showed again that autophagy is a similar processing pathway for both APP and APLP1 in responses to stresses in neuronal cells. As production of $A \beta$ is directly related with APP processing, autophagy of neuronal cells can be a cause of $A \beta$ accumulation in AD. Since present study showed APP/APLP1 is sensitive to stress induced autophagy, which can be initiated by newly developed therapeutic approaches, such as photodynamic therapy (Kessel and Oleinick, 2009), a warning of the neurodegradative disease as side effect risk in longer term treatment needs to be kept in mind and further investigated.

\section{MATERIALS AND METHODS}

\section{Reagent and plasmids}

Monoclonal APP antibody (22C11, 1:500) and polyclonal APP (369, $1: 2000)$ antibody were kind gifts from Dr. Huaxi Xu of Burmham Institute. Polyclonal APLP1 (anti-CT11, 1:2000) antibody was purchased from Upstate Biotechnology. Polyclonal $\beta$-catenin antibody (\#9582S, 1:1000) was purchased from Cell Signaling Technology, Inc (USA). Monoclonal Tubulin (sc-58667, 1:500) antibody was purchased from Santa Cruz Biotechnology, Inc (USA). MG132 was 
A

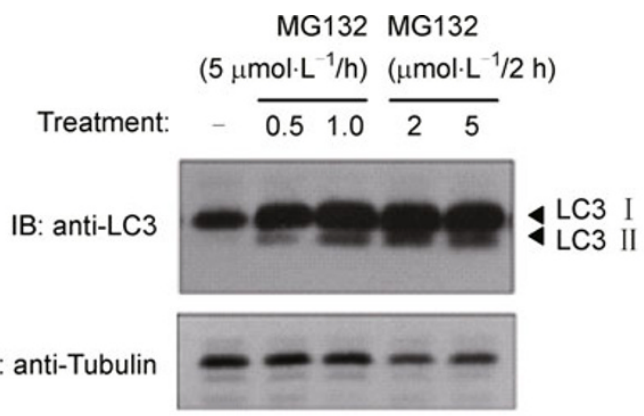

B

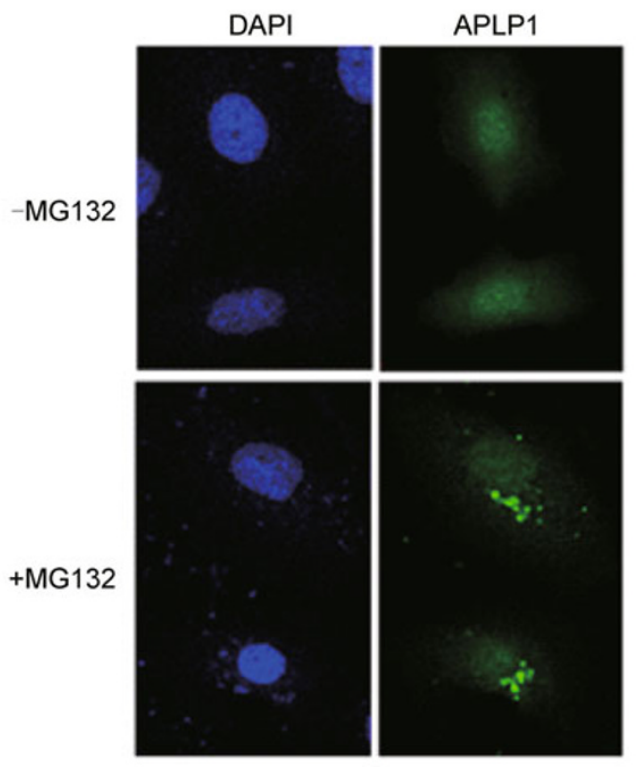

C

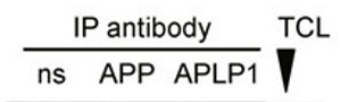

IB: anti-LC3

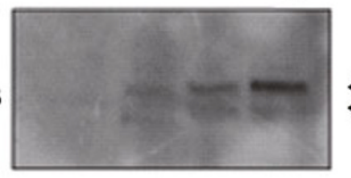

4 LC3 I

4 LC3 II

D
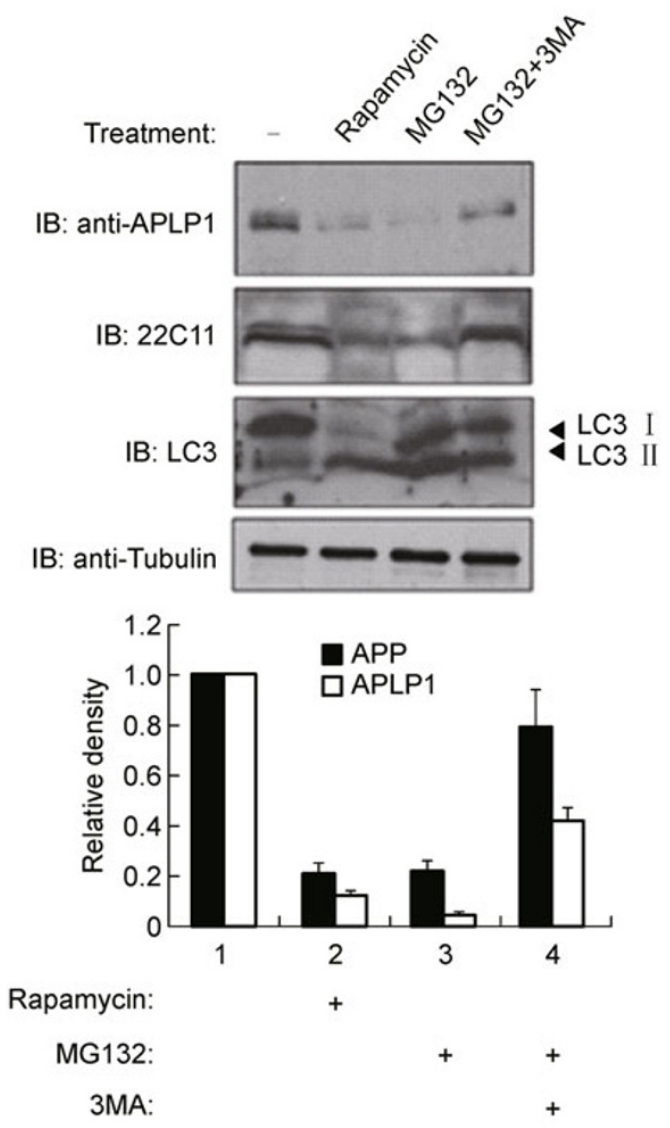

Figure 3. APPIAPLP1 is degraded through autophagy that is induced by proteasome inhibition. (A) MG132 induced cleavage of endogenous LC3. $\mathrm{N}_{2}$ a cells were transiently treated with MG132 $(5 \mu \mathrm{mol} / \mathrm{L} 0.5-1 \mathrm{~h}$ or $2-5 \mu \mathrm{mol} / \mathrm{L} 2 \mathrm{~h})$. Cells were harvested for anti-LC3 immunoblotting. (B) MG132 induced puncta of APLP1. PC12 cells were seeded in poly-D-lysine-coated

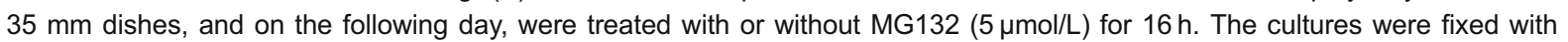
paraformaldehyde and permeabilized with Triton X-100. Then cells were incubated with rabbit anti-APLP1 primary antibody, and rhodamine-conjugated anti-mouse or FITC-conjugated anti-rabbit secondary antibodies. The nuclei were stained in blue with 4, 6diamidino-2-phenylindole. (C) Endogenous association between APLP1/APP and LC3. N2 a cells were harvested for anti-APP (369), anti-APLP1 or control anti-nonspecific (ns) immunoprecipitation (IP). APLP1 or APP-associated LC3 were revealed by anti-LC3 immunoblotting. TCL, total cell lysis. (D) Autophagy inhibitor 3MA rescued the MG132-induced APLP1/APP protein instability. $\mathrm{N}_{2} \mathrm{a}$ cells were treated with MG132, rapamycin or 3MA (3-methyl adenine) for $4 \mathrm{~h}$ as indicated; cells were harvested for anti-LC3, antiAPP (22C11) or anti-APLP1 immunoblotting. Tubulin was employed as a loading control. Quantative analysis was shown below $(n=3)$. 

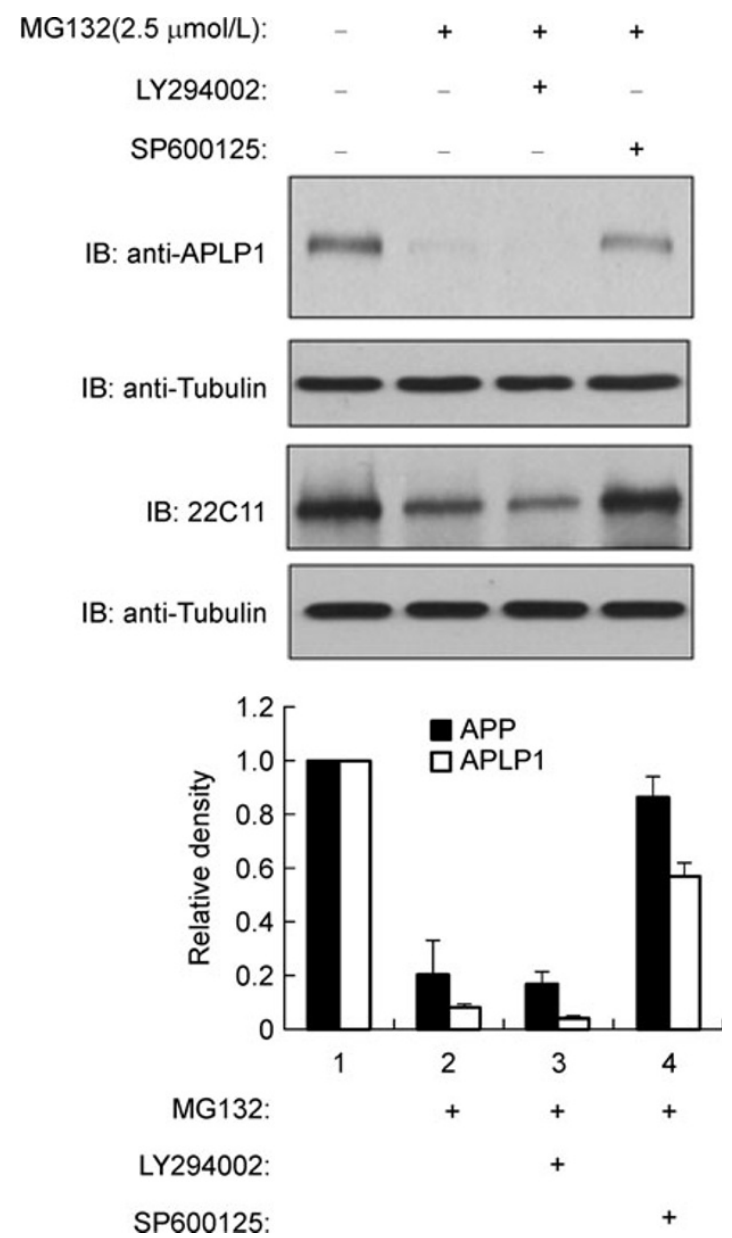

Figure 4. JNK kinase activity is required for MG132induced APLP1/APP protein proteolysis. JNK inhibitor SP600125 rescued the MG132 induced APP/APLP1 protein level. $\mathrm{N}_{2}$ a cells were treated with MG132, SP600125 or LY294002 for $2 \mathrm{~h}$ as indicated; cells were harvested for antiAPLP1 or anti-APP (22C11) immunoblotting. Tubulin was used as a loading control. Quantative analysis was shown below $(n=3)$.

purchased from Calbiochem (USA). LY294002, Rapamycin, PD98059, Forskolin and 3MA were purchased from Sigma (USA).

\section{Cell culture}

$\mathrm{N}_{2} \mathrm{a}$ and PC12 cells were cultured in Dulbecco's modified Eagle's medium (DMEM) supplemented with $10 \%$ fetal bovine serum (Hyclone) and incubated at $37^{\circ} \mathrm{C}$ in a humidified atmosphere of $5 \%$ $\mathrm{CO}_{2}$.

\section{Immunoprecipitation and immunoblotting}

As previously described (Zhang et al., 2004, 2006; Zhou et al., 2008; Zhang et al., 2011), cells were lysed with $1 \mathrm{~mL}$ of lysis buffer (20 mmol/L Tris-HCl, pH 7.4, 2 mmol/L EDTA, $25 \mathrm{mmol} / \mathrm{L} \mathrm{NaF,} 1 \%$ Triton X-100) supplemented with protease inhibitors (Sigma) for
$30 \mathrm{~min}$ at $4^{\circ} \mathrm{C}$. After centrifugation at $12,000 \mathrm{~g}$ for $15 \mathrm{~min}$, the lysates were immunoprecipitated with specific antibody and protein ASepharose (Zymed Laboratories Inc.) for $3 \mathrm{~h}$ at $4^{\circ} \mathrm{C}$. Then, the precipitants were washed three times with washing buffer $(50 \mathrm{mmol} / \mathrm{L}$ Tris- $\mathrm{HCl}, \mathrm{pH} 8.0,150 \mathrm{mmol} / \mathrm{L} \mathrm{NaCl}, 1 \%$ Nonidet $\mathrm{P}-40,0.5 \%$ sodium deoxycholate, and $0.1 \%$ SDS), and the immune complexes were eluted with sample buffer containing $1 \%$ SDS for $5 \mathrm{~min}$ at $95^{\circ} \mathrm{C}$ and analyzed by SDS-PAGE. Immunoblotting was performed with specific primary antibody and secondary anti-mouse or anti-rabbit antibodies that were conjugated to horseradish peroxidase (Amersham Biosciences). Proteins were visualized by chemiluminescence.

\section{Immunofluorescence}

As previously described (Zhou et al., 2008), PC12 cells grown on collagen coated glass coverslips were washed twice with PBS, fixed with $4 \%$ paraformaldehyde in PBS for $15 \mathrm{~min}$, permeabilized with $0.1 \%$ Triton X-100 for $10 \mathrm{~min}$, and blocked with 3\% BSA in PBS for $60 \mathrm{~min}$. The cells were then incubated with primary antibodies diluted in TBST $(20 \mathrm{mmol} / \mathrm{L}$ Tris- $\mathrm{HCl}, \mathrm{pH} 7.6,137 \mathrm{mmol} / \mathrm{L} \mathrm{NaCl}$, $0.1 \%$ Tween 20 ) for $3 \mathrm{~h}$ and washed twice with $\mathrm{p}$ PBS and incubated with fluorescein isothiocyanate (FITC) conjugated anti-mouse or antirabbit antibodies for an additional $40 \mathrm{~min}$. The nuclei were counterstained with 4, 6-diamidino-2-phenylindole (Sigma). Samples were examined under an Olympus Fluoview 500 microscope.

\section{Real-time RT-PCR}

Total RNA was isolated using Trizol (Roche, Switzerland) reagent and the genomic DNA was removed by DNase (Takara, Japan). Two microgram RNA was reverse-transcribed at $42^{\circ} \mathrm{C}$ for $45 \mathrm{~min}$ in a $20 \mu \mathrm{L}$ reaction mixture using the Reverse Transcription System (Promega, USA). Sequences for the forward primer and reverse primer are as follows: 5'-CAGATTAATGAGGTGATGCGTGAA3' (APLP1 forward), 5'-GTCGGCTTTAGGCAGGTTCTT-3' (APLP1 reverse); 5'-GCTGGCTGAACCCCAGATT-3' (APP forward), 5'-CCCACTTCCCATTCTGGACAT-3' (APP reverse); and 5'AGATCATTGACCTCGTGTTGGA-3' (Tubulin forward), 5'ACCAGTTCCCCCACCAAAG-3' (Tubulin reverse). The reaction system and procession was employed as previously described (Zhou et al., 2008).

\section{ACKNOWLEDGEMENTS}

We are grateful to Dr. Huaxi $\mathrm{Xu}$ of Burmham institute for APP antibodies. This work was supported by National Natural Science Foundation of China (Grant No. 30900748).

\section{ABBREVIATIONS}

3-MA, 3-methyladenine; AD, Alzheimer's disease; APP, amyloid precursor protein; APLP1, amyloid precursor-like protein 1; $\mathrm{CHX}$, cycloheximide; IB, immunoblotting; IP, immunoprecipitation

\section{REFERENCES}

Aguzzi, A., and Haass, C. (2003). Games played by rogue proteins in prion disorders and Alzheimer's disease. Science 302, 814-818.

Beyreuther, K., Bush, A.I., Dyrks, T., Hilbich, C., König, G., Mönning, 
U., Multhaup, G., Prior, R., Rumble, B., Schubert, W., et al.(1991). Mechanisms of amyloid deposition in Alzheimer's disease. Ann $\mathrm{N}$ Y Acad Sci 640, 129-139.

Beyreuther, K., Multhaup, G., Mönning, U., Sandbrink, R., Beher, D., Hesse, L., Small, D.H., and Masters, C.L. (1996). Regulation of APP expression, biogenesis and metabolism by extracellular matrix and cytokines. Ann N Y Acad Sci 777, 74-76.

Cao, X., and Südhof, T.C. (2001). A transcriptionally [correction of transcriptively] active complex of APP with Fe65 and histone acetyltransferase Tip60. Science 293, 115-120.

Cataldo, A.M., Paskevich, P.A., Kominami, E., and Nixon, R.A. (1991). Lysosomal hydrolases of different classes are abnormally distributed in brains of patients with Alzheimer disease. Proc Natl Acad Sci U S A 88, 10998-11002.

Chen, M., and Yankner, B.A. (1991). An antibody to beta amyloid and the amyloid precursor protein inhibits cell-substratum adhesion in many mammalian cell types. Neurosci Lett 125, 223-226.

Coulson, E.J., Barrett, G.L., Storey, E., Bartlett, P.F., Beyreuther, K., and Masters, C.L. (1997). Down-regulation of the amyloid protein precursor of Alzheimer's disease by antisense oligonucleotides reduces neuronal adhesion to specific substrata. Brain Res 770 , 72-80.

Dash, P.K., and Moore, A.N. (1993). Inhibitors of endocytosis, endosome fusion, and lysosomal processing inhibit the intracellular proteolysis of the amyloid precursor protein. Neurosci Lett 164, 183-186.

Golde, T.E., Estus, S., Younkin, L.H., Selkoe, D.J., and Younkin, S.G. (1992). Processing of the amyloid protein precursor to potentially amyloidogenic derivatives. Science 255, 728-730.

Hedera, P., and Turner, R.S. (2002). Inherited dementias.[vii.] Neurol Clin 20, 779-808, vii.

Jin, L.W., Ninomiya, H., Roch, J.M., Schubert, D., Masliah, E., Otero, D.A., and Saitoh, T. (1994). Peptides containing the RERMS sequence of amyloid beta/A4 protein precursor bind cell surface and promote neurite extension. J Neurosci 14, 5461-5470.

Kaden, D., Voigt, P., Munter, L.M., Bobowski, K.D., Schaefer, M., and Multhaup, G. (2009). Subcellular localization and dimerization of APLP1 are strikingly different from APP and APLP2. J Cell Sci 122, 368-377.
Kessel, D., and Oleinick, N.L. (2009). Initiation of autophagy by photodynamic therapy. Methods Enzymol 453, 1-16.

Liang, C.C., Wang, C., Peng, X., Gan, B., and Guan, J.L. (2010). Neural-specific deletion of FIP200 leads to cerebellar degeneration caused by increased neuronal death and axon degeneration. J Biol Chem 285, 3499-3509.

Mizushima, N. (2005). A(beta) generation in autophagic vacuoles. J Cell Biol 171, 15-17.

Muresan, Z., and Muresan, V. (2005). c-Jun NH2-terminal kinaseinteracting protein-3 facilitates phosphorylation and controls localization of amyloid-beta precursor protein. J Neurosci 25, 3741-3751.

Shimizu, S., Konishi, A., Nishida, Y., Mizuta, T., Nishina, H., Yamamoto, A., and Tsujimoto, Y. (2010). Involvement of JNK in the regulation of autophagic cell death. Oncogene 29, 2070 2082.

Soba, P., Eggert, S., Wagner, K., Zentgraf, H., Siehl, K., Kreger, S., Löwer, A., Langer, A., Merdes, G., Paro, R., et al. (2005). Homoand heterodimerization of APP family members promotes intercellular adhesion. EMBO J 24, 3624-3634.

Tanzi, R.E., McClatchey, A.I., Lamperti, E.D., Villa-Komaroff, L., Gusella, J.F., and Neve, R.L. (1988). Protease inhibitor domain encoded by an amyloid protein precursor mRNA associated with Alzheimer's disease. Nature 331, 528-530.

Zhang, L., Gao, X., Wen, J., Ning, Y., and Chen, Y.G. (2006). Dapper 1 antagonizes Wnt signaling by promoting dishevelled degradation. J Biol Chem 281, 8607-8612.

Zhang, L., Zhou, F., van Laar, T., Zhang, J., van Dam, H., and Ten Dijke, P. (2011). Fas-associated factor 1 Antagonizes Wnt Signaling by Promoting \{beta\}-catenin Degradation. Mol Biol 22,1617-1624.

Zhang, L., Zhou, H., Su, Y., Sun, Z., Zhang, H., Zhang, L., Zhang, Y., Ning, Y., Chen, Y.G., and Meng, A. (2004). Zebrafish Dpr2 inhibits mesoderm induction by promoting degradation of nodal receptors. Science 306, 114-117.

Zhou, F., Zhang, L., Wang, A., Song, B., Gong, K., Zhang, L., Hu, M., Zhang, X., Zhao, N., and Gong, Y. (2008). The association of GSK3 beta with E2F1 facilitates nerve growth factor-induced neural cell differentiation. J Biol Chem 283, 14506-14515. 